\title{
Prevalence and associated factors of hypertension among veterans of the Indian Gorkha regiments living in Pokhara Metropolitan City, Nepal
}

Abhishek Sapkota ${ }^{1 *}$, Dinesh Neupane ${ }^{1,2}$, Aamod Dhoj Shrestha ${ }^{1,3}$, Tara Ballav Adhikari, ${ }^{1,3}$, Craig Steven McLachlan ${ }^{4}$ and Naveen Shrestha ${ }^{5}$

\begin{abstract}
Background: Hypertension is a major preventable risk factor for cardiovascular disease. Occupational factors such as having served or serving in armed forces may be associated with hypertension. This study aimed to assess the prevalence and factors associated with hypertension among veterans of the Indian Gorkha army living in western Nepal.

Methods: A community-based cross-sectional study was conducted among the veterans living in the Pokhara metropolitan city. Data on blood pressure (BP), anthropometric measurements, and behavioral factors were collected by face-to-face interviews using the World Health Organization's non-communicable disease risk factor surveillance (STEPS) tool. Hypertension was defined as systolic blood pressure (BP) $\geq 140 \mathrm{~mm} \mathrm{Hg}$ and/or diastolic BP of $\geq 90 \mathrm{~mm} \mathrm{Hg}$ or currently on antihypertensive medication.

Results: The age-adjusted prevalence of hypertension was $66.2 \%$ among the study participants (317). Mean systolic and diastolic blood pressure was $144.5 \mathrm{mmHg}( \pm 18.3)$ and $89.3 \mathrm{mmHg}( \pm 16.0)$, respectively. Among the hypertensive participants, $67 \%$ were aware of their disease, $90 \%$ of them were under treatment, and $14 \%$ of the individuals who received treatment had their hypertension under control. The proportion of smokers was $12.9 \%$ and alcohol drinker was $86.1 \%$. One-fourth (25.9\%) of the participants had a family history of hypertension. Veterans aged 55-64 years had higher odds (AOR: $5.3 ; 95 \% \mathrm{Cl}: 1.8-15.9 ; p=0.003$ ) of being associated with hypertension as compared to 35-44 years. Being a current alcohol drinker (AOR: 2.5; $95 \%$ Cl: 1.4-4.5; $p=$ 0.003), overweight (AOR: 1.9; $95 \%$ Cl: $1.0-3.5 ; p=0.04$ ), obese (AOR: $3.1 ; 95 \% \mathrm{Cl}: 1.1-8.3 ; p=0.03$ ) and family history of hypertension (AOR: 2.9; $95 \%$ Cl: 1.5-5.8; $p=0.002$ ) were independently associated with hypertension.

Conclusions: Hypertension was prevalent in retired Nepal veterans. Hypertension was associated with a number of modifiable lifestyle and behavioral factors. Our findings suggest the need for screening, education and management of Nepal veterans for hypertension.
\end{abstract}

Keywords: Hypertension, veterans, retired army, NCDs, occupational health, Nepal

\footnotetext{
* Correspondence: abhishek.sapkota2153@gmail.com

${ }^{1}$ Nepal Development Society, Chitwan, Nepal

Full list of author information is available at the end of the article
} 


\section{Background}

Globally, hypertension is a significant risk factor for cardiovascular disease (CVD) [1]. The age-standardized global prevalence of hypertension is $31.1 \%[2,3]$. It is estimated that $18 \%$ of adults in the low- and middleincome countries (LMICs) are hypertensive, of which two-thirds remain untreated [4]. In South Asia, after Afghanistan, Nepal has the highest burden of hypertension with an estimated prevalence to be circa $28 \%[5,6]$. Occupational factors can influences long term stress responses that can result in hypertension. For example, having served or serving in the armed forces maybe associated with increased risk for developing hypertension [7, 8]. In the United States of America (USA), protective service occupations had a significantly increased prevalence of hypertension compared to management occupations when controlling for age. Furthermore, $51 \%$ of veterans have been reported to be hypertensive [9]. Similarly, an analysis of 20 years' data of American veterans showed that $42 \%$ of them developed CVDs [10]. Nearly $54 \%$ of retired army officers in China were found hypertensive, whereas only $20.9 \%$ of service officers (non-retired) had hypertension [11].

There are limited studies assessing the prevalence of hypertension among army veterans in Nepal. A study conducted among war veterans in eastern Nepal showed a $35.6 \%$ prevalence of raised blood pressure among veterans, and the odds of being hypertensive was higher compared to farmers and labors [7]. It is unknown whether Indian army veterans in Nepal have similar levels of hypertension as reported in other countries. Our aim is to estimate the prevalence of hypertension and associated factors among veterans of the Indian Gorkha army living in Pokhara Metropolitan City, of Western Nepal.

\section{Methods}

\section{Study design and study population}

A community-based cross-sectional study was conducted in Pokhara metropolitan City. The study included veterans of the Indian Gorkha army who are permanent residents of the Pokhara metropolitan city.

\section{Sample size calculation and sampling procedure}

The required sample size of the study was 317, determined by assuming $20 \%$ prevalence of hypertension [12], allowable error $(\alpha)$ of 0.05 , design effect of 1.2 , and confidence interval of $95 \%$. Assuming a response rate of $90 \%$, the sample size was raised to 348 for this study. The sampling frame was obtained by contacting the chairperson responsible for each retired group of veterans, across 6 localities of Pokhara metropolitan city. Each veteran was assigned a number in chronological order. Then, 348 veterans were selected using lottery method. Regarding the number of young participants, the minimum age required to be eligible for the Indian army is 18 years, and they can retire after 18 years in service. Only a few of the military officers retire after 18 years. Those who retire at young age leave the country to work as security officers in foreign country. So, only few of the young participants were available at the time of the study.

\section{Data collection procedure}

Face to face interview and physical measurements wereconducted at the respondents' households. The study tool was adapted from the World Health Organization's validated STEPS tools version 3.1 [13], which have been validated in Nepali by Nepal Health Research Council (NHRC) [14]. Anthropometric measurements were taken using standardized techniques and calibrated equipment.

\section{Blood pressure measurement}

Blood pressure was measured using a digital measuring device (Dr. Morepen Model BP-09) with participants sitting after resting for at least fifteen minutes. Three BP measurements were taken at five-minute intervals. The average of the last two measurements was included in the analysis. Hypertension was defined as a systolic BP of $\geq 140 \mathrm{~mm} \mathrm{Hg}$ and/or diastolic BP of $\geq 90 \mathrm{~mm} \mathrm{Hg}$ or the use of antihypertensive medication [15].

\section{Socio-demographic variables}

Socio-demographic variables included in the study were age group in years $(35-44,45-54,55-64,>64)$, and ethnicity, which was categorized into upper caste, Janajatis, and others according to the caste coding by the Government of Nepal [16].

\section{Behavioral variables}

Current smoker was defined as smoking at least one cigarette in the last 30 days and current alcohol consumption was defined as at least one drink in the last 30 days. Low physical activity was defined as those who scored less than 3,000 metabolic equivalents of the task of moderate or vigorous activities per week, while those with more than 3,000 metabolic equivalents of the task were defined as adequate physical activity [17].

\section{Anthropometric measurements}

Weight was measured using a digital scale, and height was measured using a portable stature scale. Body mass index (BMI) was calculated by dividing weight in kilogram by square of height in meters. BMI was classified as underweight $\left(<18.5 \mathrm{~kg} / \mathrm{m}^{2}\right)$, normal $\left(\geq 18.5 \mathrm{~kg} / \mathrm{m}^{2}\right.$ to $\left.<25 \mathrm{~kg} / \mathrm{m}^{2}\right)$, overweight $\left(\geq 25 \mathrm{~kg} / \mathrm{m}^{2}\right.$ to $\left.<30 \mathrm{~kg} / \mathrm{m}^{2}\right)$ and obesity ( $\geq 30 \mathrm{~kg} /$ $\mathrm{m}^{2}$ ). Waist and hip circumferences were measured using John's non-stretchable measuring tape. As all participants were male, participants with waist circumference $\geq 90$ centimeters were defined to have central obesity [18]. 


\section{Awareness, treatment, and control of hypertension}

Participants who reported that a physician ever told them they had hypertension were considered aware of their hypertensive conditions. Participants receiving any kind of anti-hypertensive drugs in the last two weeks were categorized as undergoing treatment [19]. Control of hypertension was defined as hypertensive participants having an average systolic $\mathrm{BP}<140 \mathrm{~mm}$ $\mathrm{Hg}$ and an average diastolic $\mathrm{BP}<90 \mathrm{~mm} \mathrm{Hg}$ [19].

\section{Data analysis}

The collected data were checked for consistency and completeness and were entered in EpiData version 3.1(The EpiData Association, Odense, Denmark) and analyzed using IBM SPSS Statistics for Windows, version 20.0(Armonk, NY: IBM Corp). Frequency distribution, mean and percentage were calculated as descriptive analysis. A multiple logistic regression analysis was performed with hypertension as the dependent variable and age, sex, ethnicity, smoking, alcohol consumption, physical activity, BMI, central obesity, and family history of hypertension as the independent variables. Those variables with a p-value $\leq 0.05$ were considered statistically significant associations.

\section{Results}

\section{Socio-demographic characteristics}

A total of 317 veterans participated in the study, with a response rate of $91 \%$. All were male between 39 and 92 years of old. The mean age $( \pm \mathrm{SD})$ was $62( \pm 11.8)$ years. Table 1 shows the socio-demographic and behavioral characteristics of the study participants. The majority of the participants were above 64 years $(40.1 \%)$ and Janajati (87.4\%). The proportion of current smokers, current alcohol drinkers, low physical activity, family history of hypertension, overweight and central obesity were $12.9 \%$, $55.5 \%, 18.6 \%, 25.9 \%, 51.4 \%$, and $6.6 \%$, respectively.

\section{Prevalence of Hypertension}

The mean (SD) systolic and diastolic BP readings were 144.5 (18.3) and 89.3(16.0) $\mathrm{mmHg}$, respectively. The age-adjusted prevalence of hypertension was $66.2 \%$. Among all individuals identified as hypertensive, $67 \%$ were aware of their condition. Nearly $90 \%$ of those aware of being hypertensive were receiving treatment. However, less than one-fifth of the treated subjects had their hypertension under control (14\%).

\section{Factors associated with Hypertension}

Table 2 presents the association of hypertension with different risk factors. Veterans aged 55-64 years had higher odds (AOR: 5.3; $95 \% \mathrm{CI}$ : $1.8-15.9 ; p=0.003$ ) of being associated with hypertension as compared to 35-
Table. 1 Socio-demographic and behavioral characteristics of the study participants

\begin{tabular}{|c|c|c|}
\hline Characteristics $(n=317)$ & Frequency & Percentage \\
\hline \multicolumn{3}{|l|}{ Age } \\
\hline $35-44$ years & 20 & 6.3 \\
\hline $45-54$ years & 73 & 23 \\
\hline $55-64$ years & 97 & 30.6 \\
\hline$>64$ years & 127 & 40.1 \\
\hline \multicolumn{3}{|l|}{ Ethnicity } \\
\hline Upper caste & 38 & 12 \\
\hline Janajati & 277 & 87.4 \\
\hline Others & 2 & 0.6 \\
\hline \multicolumn{3}{|l|}{ Currently Smoking } \\
\hline Yes & 41 & 12.9 \\
\hline No & 276 & 87.1 \\
\hline \multicolumn{3}{|c|}{ Current alcohol consumption } \\
\hline Yes & 176 & 55.5 \\
\hline No & 141 & 44.5 \\
\hline \multicolumn{3}{|l|}{ Physical activity } \\
\hline Low & 59 & 18.6 \\
\hline Adequate & 258 & 81.4 \\
\hline \multicolumn{3}{|c|}{ Family History of Hypertension } \\
\hline Yes & 82 & 25.9 \\
\hline No & 235 & 74.1 \\
\hline \multicolumn{3}{|l|}{ BMI } \\
\hline Underweight & 2 & 0.6 \\
\hline Normal & 107 & 33.8 \\
\hline Overweight & 163 & 51.4 \\
\hline Obese & 45 & 14.2 \\
\hline \multicolumn{3}{|l|}{ Central Obesity } \\
\hline Yes & 21 & 6.6 \\
\hline No & 296 & 93.4 \\
\hline
\end{tabular}

44 years. Being a current alcohol drinker (AOR: 2.5, $95 \%$ CI: 1.4-4.5; $p=0.003$ ), overweight (AOR: 1.9, $95 \%$ CI: $1.0-3.5 ; p=0.04$ ), obese (AOR: 3.1, $95 \%$ CI: 1.1-8.3; $p=0.03$ ) and family history of hypertension (AOR: 2.9, $95 \%$ CI: $1.5-5.8 ; p=0.002$ ) were independently associated with hypertension. Factors such as ethnicity, current smoking, physical activity, and central obesity were not significantly associated with hypertension.

\section{Discussion}

This study found the age-adjusted prevalence of hypertension to be $66.2 \%$ in army veterans of the IndiaGorkha regiment residing in Pokhara Metropolitan city of Western, Nepal. In addition, this prevalence was higher than that of previous study among war veterans 
Table. 2 Association between hypertension and major risk factors

\begin{tabular}{|c|c|c|c|c|c|c|}
\hline \multirow{2}{*}{$\begin{array}{l}\text { Risk factors } \\
(N=317)\end{array}$} & \multicolumn{2}{|c|}{ Hypertension } & \multirow[t]{2}{*}{ OR(95 \%Cl) } & \multirow[t]{2}{*}{$p$-value } & \multirow{2}{*}{$\begin{array}{l}\text { AOR }(95 \% \\
\text { Cl) }\end{array}$} & \multirow[t]{2}{*}{$p$-value } \\
\hline & Yes(\%) & No (\%) & & & & \\
\hline \multicolumn{7}{|c|}{ Age (in years) } \\
\hline $35-44$ years & $10(50)$ & $10(50)$ & Ref & & & \\
\hline $45-54$ years & $41(56.1)$ & $32(43.8)$ & $1.3(0.5-3.5)$ & 0.6 & $1.5(0.5-4.6)$ & 0.44 \\
\hline $55-64$ years & $74(76.3)$ & $23(23.7)$ & $3.21(1.2-8.7)$ & 0.02 & $5.3(1.8-15.9)$ & 0.003 \\
\hline$>64$ years & $91(71.7)$ & $36(28.5)$ & $2.52(0.9-6.6)$ & 0.06 & $5.5(1.8-16.6)$ & 0.002 \\
\hline \multicolumn{7}{|l|}{ Ethnicity } \\
\hline Upper caste & $28(73.7)$ & $10(26.3)$ & Ref & & & \\
\hline Janajati & 187(67.5) & $90(32.5)$ & $0.7(0.4-1.6)$ & 0.44 & $0.6(0.2-1.4)$ & 0.24 \\
\hline Others & $1(50)$ & $1(50)$ & $0.4(0.2-6.3)$ & 0.48 & $0.3(0.0-5.7)$ & 0.41 \\
\hline \multicolumn{7}{|c|}{ Currently alcohol user } \\
\hline No & $86(61)$ & $55(39)$ & Ref & & & \\
\hline Yes & 130(73.9) & $46(26.1)$ & $1.8(1.1-2.9)$ & 0.02 & $2.5(1.4-4.5)$ & 0.003 \\
\hline \multicolumn{7}{|c|}{ Current smoker } \\
\hline No & 188(68.1) & 88(31.9) & Ref & & & \\
\hline Yes & $28(68.3)$ & 13(31.7) & $1.0(0.5-2.0)$ & 0.98 & $1.0(0.4-2.4)$ & 0.96 \\
\hline \multicolumn{7}{|c|}{ Physical activity } \\
\hline Adequate & $174(67.4)$ & $84(32.6)$ & Ref & & & \\
\hline Low & $42(71.2)$ & $17(28.8)$ & $1.2(0.6-2.2)$ & 0.58 & $1.8(0.9-3.8)$ & 0.13 \\
\hline \multicolumn{7}{|c|}{ Body Mass Index (Kg/m2) } \\
\hline Normal & $63(58.9)$ & $44(41.1)$ & Ref & & & \\
\hline Underweight & $1(50)$ & $1(50)$ & $0.7(0.0-11.5)$ & 0.80 & $2.8(0.1-64.8)$ & 0.52 \\
\hline Overweight & 116(71.2) & $47(28.8)$ & $1.7(1.0-2.9)$ & 0.04 & $1.9(1.0-3.5)$ & 0.04 \\
\hline Obese & $36(80)$ & $9(20)$ & $2.8(1.2-6.4)$ & 0.02 & $3.1(1.1-8.3)$ & 0.03 \\
\hline \multicolumn{7}{|c|}{ Central obesity $(\mathrm{cm})$} \\
\hline No & 199(67) & $97(33)$ & Ref & & & \\
\hline Yes & $17(81)$ & $4(19)$ & $2.1(0.7-6.3)$ & 0.20 & $1.5(0.4-5.4)$ & 0.53 \\
\hline \multicolumn{7}{|c|}{ Family history of hypertension } \\
\hline No & 149(63.4) & $86(36.6)$ & Ref & & & \\
\hline Yes & $67(81.7)$ & 15(18.3) & $2.6(1.4-4.8)$ & 0.003 & $2.9(1.5-5.8)$ & 0.002 \\
\hline
\end{tabular}

of Nepal that showed a prevalence of $35.6 \%$ in 2007 [7]. This prevalence is higher than the WHO global report and other population-based studies in Nepal $[3,12,20,21]$. We acknowledge that our age groups, ethnicity, and occupation of participants are different than the WHO report.

From a global perspective, the prevalence of hypertension in our study is higher than a meta-analysis on prevalence rates of major chronic diseases in retired and in-service Chinese military officers. This metaanalysis explored 75 articles with a sample size of 90,758 , which showed an overall prevalence of $53.8 \%$ among retired officers, while it was $20.9 \%$ among inservice officers [11].

In our study, risk factors such as being a current smoker, inadequate physical activity, central obesity, and hypertension were prevalent in higher age groups, i.e., 55-64 years. Similar cardiovascular risk factors for hypertension have been previously reported in Nepal [22]. Higher age, alcohol consumption, overweight, obesity, and family history of hypertension were found to be associated with hypertension in our study. These risk factors associated with hypertension are similar for the general population in Nepal [22, 23].

The awareness rate and treatment rate of hypertension in our study were similar to a study conducted among retired troops in China which showed an awareness rate of $45.1 \%$ and a treatment rate of $94.6 \%$ [24]. However, the rate of hypertension control was high, with $62.3 \%$ [24]. On the other hand, the rate of control in our study was only $14 \%$. 
There may be some explanations for the prevalence of hypertension to be high in our studies. Firstly, we have focused on individuals in armed service after retirement. As opposed to younger active recruits may be fit and have lower hypertension rates [25]. Indeed, with aging, one would expect an increase in systolic blood pressure with aortic stiffening, particularly with smoking or alcohol intake. There was also a significant increase in BMI in those that were hypertensive as compared to those that were not. Obesity and or metabolic syndrome are risk factors once again for hypertension [26]. While there was a trend towards reduced fitness and hypertension, this was not statistically significant, despite a large component of the cohort being overweight. Finally, while not assessed, active combat can be associated with post-traumatic stress disorder that is significantly associated with increased risky behaviors such as smoking and alcohol intake which can increase cardiovascular risk [27].

The strengths of our study are a random sampling of participants, validated tools, and the measurement of blood pressure using WHO guidelines. The study also had various limitations. Firstly, the study was confined to a limited number of wards of Pokhara metropolitan. However, a reasonable sample size was obtained. Secondly, as the study was cross-sectional, hence a causal relationship between hypertension and sociodemographic and behavioral variables cannot be inferred. Thirdly, there might have been some bias in selfreported behaviors such as tobacco use, alcohol use, and physical activity. Lastly, it is acknowledged that a number of risk factors can influence hypertension development, such as additional environmental factors, however in our study we have focused on commonly reported risk factors that are modifiable for cardiovascular risk.

\section{Conclusions}

Our study concludes that the age-standardized prevalence of hypertension is high among veterans of the Indian Gorkha regiments living in Pokhara Metropolitan City. Furthermore, hypertension was found to be significantly associated with age, current alcohol use, family history of hypertension, and BMI. Behavioral interventions targeting modifiable risk factors such as obesity, smoking, and alcohol intake may be effective in reducing the burden of hypertension.

\footnotetext{
Acknowledgements

The authors would like to express their deepest and heartfelt thanks to all study participants. Special thank goes to Mr. Ram Chandra Adhikari and Mr. Kiran Adhikari for their support during the data collection.

We confirm that all methods were carried out in accordance with relevant guidelines and regulations.
}

\section{Declaration of Methods}

We confirm that all methods were carried out in accordance with relevant guidelines and regulations.

\section{Authors' contribution}

AS conceptualized the study, analyzed the data and prepared the first draft of the manuscript. All the authors critically revised the manuscript and approved the final version of the manuscript.

\section{Funding}

No specific funding was received for this study.

Availability of data and materials

The data used to support the findings of this study are available from the corresponding author upon reasonable request.

\section{Declarations}

Ethics approval and consent to participate

The study was approved by the Institutional Review Committee of Pokhara University. The written informed consent was obtained from the study participants.

\section{Consent for publication}

Not applicable.

\section{Competing interests}

The authors declare that they have no potential conflict of interest in the publication of this research output.

\section{Author details}

${ }^{1}$ Nepal Development Society, Chitwan, Nepal. ${ }^{2}$ Johns Hopkins Bloomberg School of Public Health, Baltimore, MD, USA. ${ }^{3}$ Department of Public Health, Section for Global Health, Aarhus University, Aarhus, Denmark. ${ }^{4}$ Health Faculty, Centre for Healthy Futures, Torrens University Australia, Adelaide, Australia. ${ }^{5}$ CIST College, Pokhara University, Kathmandu, Nepal.

Received: 15 January 2021 Accepted: 6 August 2021

Published online: 01 September 2021

\section{References}

1. GBD 2017 Risk Factor Collaborators. Global, regional, and national comparative risk assessment of 84 behavioural, environmental and occupational, and metabolic risks or clusters of risks for 195 countries and territories, 1990-2017: a systematic analysis for the Global Burden of Disease Study 2017. Lancet (London, England). 2018;392(10159):1923-94.

2. Mills KT, Bundy JD, Kelly TN, Reed JE, Kearney PM, Reynolds K, et al. Global Disparities of Hypertension Prevalence and Control: A Systematic Analysis of Population-Based Studies From 90 Countries. Circulation. 2016;134(6):441-50.

3. World Health Organization (WHO). A global brief on hypertension: silent killer, global public health crisis: World Health Day 2013. Geneva: World Health Organization, 2013 2013. Report No.: Contract No.: WHO/DCO/WHD/ 2013.2.

4. Sarki AM, Nduka CU, Stranges S, Kandala NB, Uthman OA. Prevalence of Hypertension in Low- and Middle-Income Countries: A Systematic Review and Meta-Analysis. Medicine. 2015;94(50):e1959.

5. World Health Organization (WHO). Global Health Observatory Data Repository.

6. Neupane D, Shrestha A, Mishra SR, Bloch J, Christensen B, McLachlan CS, et al. Awareness, Prevalence, Treatment, and Control of Hypertension in Western Nepal. American Journal of Hypertension. 2017;30(9):907-13.

7. Vaidya A, Pokharel PK, Nagesh S, Karki P, Kumar S, Majhi S. War veterans of Nepal and their blood pressure status: a population-based comparative study. Journal of Human Hypertension. 2007;21(11):900-3.

8. Mara T, Ma L-T, Wang S, Wang L, Yang F, Song J-H, et al. The prevalence rates of major chronic diseases in retired and in-service Chinese military officers (2000-2016): a meta-analysis. Military Medical Research. 2018;5(1):4

9. Fryar CD, Herrick K, Afful J, Ogden CL. Cardiovascular Disease Risk Factors Among Male Veterans, U.S., 2009-2012. Am J Prev Med. 2016;50(1):101-5.

10. Assari S. Veterans and risk of heart disease in the United States: a cohort with 20 years of follow up. Int J Prev Med. 2014;5(6):703-9.

11. Mara T, Ma L-T, Wang S, Wang L, Yang F, Song J-H, et al. The prevalence rates of major chronic diseases in retired and in-service Chinese military 
officers (2000-2016): a meta-analysis. Military Medical Research [Internet]. 2018 2018/01//; 5(1):[4 p.].

12. Hasan M, Sutradhar I, Akter T, Das Gupta R, Joshi H, Haider MR, et al. Prevalence and determinants of hypertension among adult population in Nepal: Data from Nepal Demographic and Health Survey 2016. PloS one. 2018;13(5):e0198028.

13. World Health Organization (WHO). The STEPS Instrument and Support Materials.

14. Aryal KK. Non communicable diseases risk factors: STEPS Survey Nepal 2013: Nepal Health Research Council (NHRC); 2014.

15. World Health Organization (WHO). Hypertension control: report of a WHO Expert Committee. 1996.

16. Central Beuaro of Statistics (CBS)-Government of Nepal. National population and housing census 2011. National Report. 2012.

17. World Health Organization (WHO). WHO STEPS surveillance manual: the WHO STEPwise approach to chronic disease risk factor surveillance. World Health Organization, 20059241593830.

18. Misra A, Vikram N, Gupta R, Pandey R, Wasir J, Gupta V. Waist circumference cutoff points and action levels for Asian Indians for identification of abdominal obesity. International journal of obesity. 2006;30(1):106-11.

19. Dong G, Sun Z, Zheng L, Li J, Zhang X, Zhang X, et al. Prevalence, awareness, treatment, and control of hypertension in rural adults from Liaoning Province, northeast China. Hypertension Research. 2007;30(10):951-8.

20. Ofori SN, Obosi J. Prevalence of hypertension among office workers in a multi-national company in the Niger-Delta with the 2017 American College of Cardiology/American Heart Association Blood Pressure Guidelines. Preventive medicine reports. 2019;15:100899.

21. Neupane D, McLachlan CS, Mishra SR, Olsen MH, Perry HB, Karki A, et al. Effectiveness of a lifestyle intervention led by female community health volunteers versus usual care in blood pressure reduction (COBIN): an openlabel, cluster-randomised trial. The Lancet Global Health. 2018;6(1):e66-e73.

22. Dhungana RR, Pandey AR, Bista B, Joshi S, Devkota S. Prevalence and Associated Factors of Hypertension: A Community-Based Cross-Sectional Study in Municipalities of Kathmandu, Nepal. International Journal of Hypertension. 2016;2016:10.

23. Aryal KK, Mehata S, Neupane S, Vaidya A, Dhimal M, Dhakal P, et al. The Burden and Determinants of Non Communicable Diseases Risk Factors in Nepal: Findings from a Nationwide STEPS Survey. PloS one. 2015;10(8): e0134834.

24. ZHENG Z-m, LI G-I, YANG M-y. Research on incidence and prevention of hypertension in retired army cadres. Journal of Navy Medicine. 2007;1.

25. Wenzel D, Souza JMPd, Souza SBd. Prevalence of arterial hypertension in young military personnel and associated factors. Revista de saude publica. 2009:43:789-95.

26. Matsuda M, Shimomura I. Increased oxidative stress in obesity: implications for metabolic syndrome, diabetes, hypertension, dyslipidemia, atherosclerosis, and cancer. Obesity research \& clinical practice. 2013;7(5): e330-e41.

27. Dedert EA, Calhoun PS, Watkins LL, Sherwood A, Beckham JC. Posttraumatic stress disorder, cardiovascular, and metabolic disease: a review of the evidence. Annals of Behavioral Medicine. 2010;39(1):61-78.

\section{Publisher's Note}

Springer Nature remains neutral with regard to jurisdictional claims in published maps and institutional affiliations.

Ready to submit your research? Choose BMC and benefit from:

- fast, convenient online submission

- thorough peer review by experienced researchers in your field

- rapid publication on acceptance

- support for research data, including large and complex data types

- gold Open Access which fosters wider collaboration and increased citations

- maximum visibility for your research: over $100 \mathrm{M}$ website views per year

At BMC, research is always in progress.

Learn more biomedcentral.com/submissions 